\title{
Bilateral Synchronous Testicular Seminoma in a Patient with Bilateral Cryptorchidism
}

\author{
Dilasma Ghartimagar, ${ }^{1}$ Arnab Ghosh, ${ }^{1}$ Manish Kiran Shrestha, ${ }^{2}$ Duk Bahadur Chettri, ${ }^{3}$ Santosh Shrestha, ${ }^{4}$ Rishi \\ Kumar Sherchan ${ }^{5}$ \\ 'Department of Pathology, Manipal Teaching Hospital, Pokhara, Nepal, ${ }^{2}$ Department of Radiology, Gandaki Medical \\ College, Pokhara, Nepal, ${ }^{3}$ Advance Lab and Research Center, Pokhara, Nepal, ${ }^{4}$ Department of Surgery, Western Regional \\ Hospital, Pokhara, Nepal, ${ }^{5}$ Department of Oncology, Manipal Teaching Hospital Pokhara, Nepal.
}

\section{ABSTRACT}

Cryptorchidism is a known cause of testicular tumor. The incidence of testicular tumor is 11 times more in inguinal testes and 50 times more in intra-abdominal testes. The position of the undescended testis is related to the likelihood of carcinogenesis with the intra-abdominal location having the highest risk for malignancy. Bilateral testicular tumors are rare and $80 \%$ of bilateral tumors are metachronous. Synchronous bilateral testicular tumors are rare and bilateral synchronous testicular seminoma in a patient with bilateral cryptorchidism is very rare.

Keywords: bilateral; cryptorchidism; seminoma; synchronous; testes.

\section{INTRODUCTION}

The incidence of testicular germ cell tumor is $0.005 \%$ in general population and it incurs $1-5 \%$ increased risk of developing germ cell tumor in contralateral testis. ${ }^{1}$ Cryptorchidism is a known risk factor for testicular tumor. ${ }^{2}$ The position of the undescended testis is related to the likelihood of carcinogenesis with the intra-abdominal location having the highest risk for malignancy. ${ }^{3}$ Bilateral testicular tumors are rare and $80 \%$ of bilateral tumors are metachronous. Bilateral synchronus testicular tumor in bilateral cryptorchidism is very rare, ${ }^{1}$ and to our knowledge this is the second case being reported in world literature.

\section{CASE REPORT}

A 40 year old male from Kusma Parbat, Hindu by religion and married for 15 years presented with severe abdominal pain for two days. He had on and off dull aching pain in right iliac fossa for four-six weeks. On palpation, there was abdominal tenderness and firm nodular mass. There was no change in normal bowel and bladder habit. General examination of other systems was normal. Patient revealed on enquiry that both the testes were absent in scrotum since his birth. However he had been married for 15 years with a history of normal conjugal life but did not have any children. Routine urine tests, hematological test, renal and liver function tests all were normal.

Abdominal USG showed two mixed echogenic space occupying lesions measuring $13 \times 8 \mathrm{~cm}^{2}$ on the right

Correspondence: Dr. Dilasma Ghartimagar, Department of Pathology, Manipal College of Medical Sciences, Pokhara, Nepal. Email: dilasmagm@hotmail.com, Phone: +977-9840603962. 
Ghartimagar et al. Bilateral Synchronous Testicular Seminoma in a Patient with Bilateral Cryptorchidism

side and $6 \times 4 \mathrm{~cm}^{2}$ on the left side (Figure 1) and contrast enhanced computed tomogram (CECT) scan was advised. On CECT, two large well defined solid lesions were seen measuring $12.2 \times 13.7 \times 15.4 \mathrm{~cm}^{3}$ on the right side (Figure 2a) and $10.7 \times 7.7 \times 6 \mathrm{~cm}^{3}$ on the left side (Figure 2b). Radiological impression was bilateral testicular tumor with differential diagnosis (DD) of Non Hodgkin's Lymphoma (NHL) and mesenteric fibromatosis (desmoid tumor).

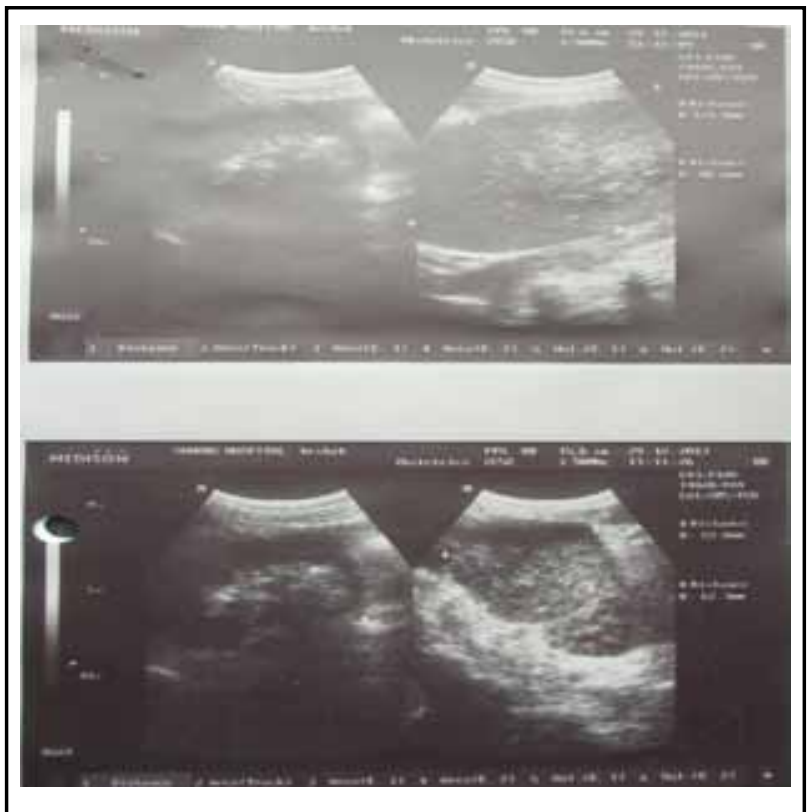

Figure 1. Ultrasonography of undescended testis presenting as an abdominal mass.

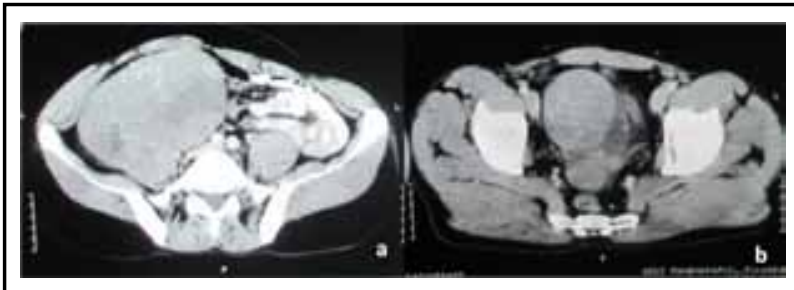

Figure 2. CT scan showing the mass in the right (2a) and left $(2 b)$ iliac foss.

Per operative, it was found that bilateral testes were absent in the scrotum. Two abdomino-pelvic masses were removed and sent for histopathology. No separate testes were found on either side. Post operative, patient revealed on enquiry that both the testes were absent in scrotum since his birth. With this history bilateral testicular tumor was considered as the first DD and serum enzyme assays were done.

The serum -fetoprotein (AFP) level was $9.2 \mathrm{ng} / \mathrm{ml}$, serum beta-human chorionic gonadotrophin (口-hCG) was $1.1 \mathrm{ng} / \mathrm{ml}$ and serum lactate dehydrogenase (LDH) was marginally elevated (519 U/L)
On gross examination, both tumors showed similar grey white cut surface without any necrosis, hemorrhage and cystic change (Figure $3 a, 3 b$ ).

On microscopy, both the tumors showed similar morphology. Tumor was composed of seminoma cells separated by thin fibrous septae and sparse lymphocytes (Figure 4a, 4b). Histopathological diagnosis of bilateral classical seminoma was made.

Post operatively, on follow up of eight months, patient has finished all four cycles of chemotherapy and he was asymptomatic.

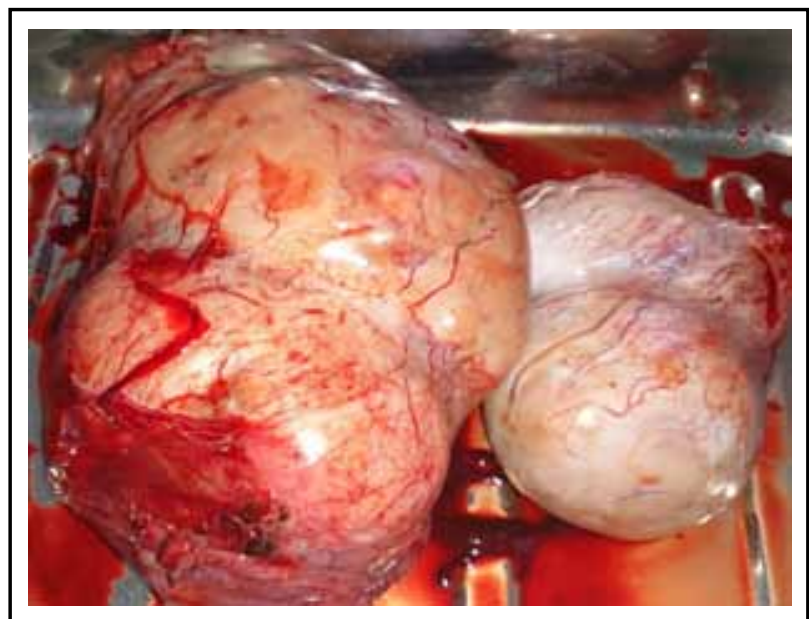

Figure 3. Testicular mass after removal in the operation theatre

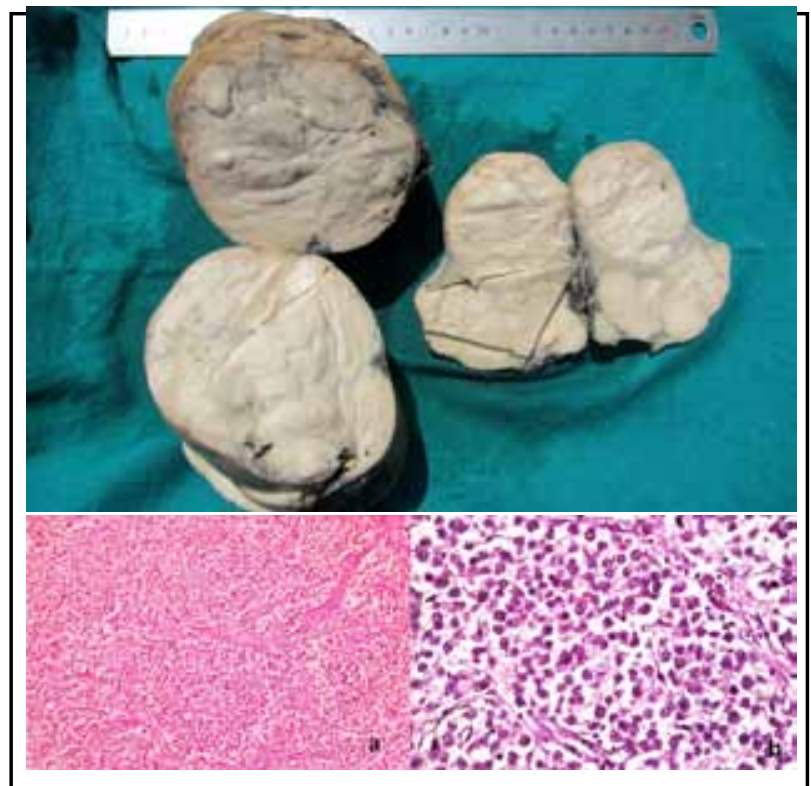

Figure 4. a) Microscopic picture showing seminoma cells separated by thin fibrous stroma. (H\&Ex10). b) High power showing polygonal cells with clear cytoplasma, round nucleus and inconspicuous nucleoli (H\&Ex40). 


\section{DISCUSSION}

Testicular cancer is the commonest cancer in males between 15-35 years of age. ${ }^{1}$ Cryptorchidism is a known cause of testicular tumor. The position of undescended testis is related to the risk of cancer. The cause of carcinogenesis is still an enigma. A high intraabdominal temperature has been incriminated as the cause of carcinogenesis in the testis. ${ }^{2}$ The incidence of testicular tumor is 50 times more in abdominal testis and 11 times more in inguinal testis. ${ }^{4}$

Painless enlargement of the testis or abdominal mass is the common mode of presentation in a cryptorchid testis. ${ }^{5}$ Rarely, an abdominal testicular tumor can cause acute abdomen, massive abdominal mass and haematuria because of adjacent visceral infiltration. ${ }^{6}$ Our patient came with a history of painless abdominal mass which was gradually enlarging in size. Patients who develop carcinoma in one testis have 500-1000 times increased risk of developing carcinoma in the contralateral testis. Approximately $0.5-7 \%$ of patients with testicular carcinoma will develop a contralateral tumor. ${ }^{1}$

A male with a tumor in a descended testis is estimated to have a $0.7 \%$ risk of developing a second testicular tumor on the contralateral side. The risk of a second testicular tumor increases to $15 \%$ when both the testes are undescended and is as high as $30 \%$ if, the second testis is intra-abdominal. ${ }^{7}$ Bilateral testicular tumors occur metachronously in $80-85 \%$ of patients and synchronously in $15-20 \% .^{8}$
Dieckmann et al found that approximately 50\% of metachronous tumors in their study had similar pathological features. ${ }^{9}$ Seminomas accounted for $80 \%$ of cases with similar pathological features, and $20 \%$ were non-seminomatous tumors. Synchronous bilateral testicular tumors account for less than $1 \%$ of cases of testicular carcinoma. Most synchronous testicular tumors are seminoma. Other tumors reported include embryonal carcinoma, teratocarcinoma and choriocarcinoma. ${ }^{1,7}$ Most bilateral testicular tumors in undescended testis present as metachronus lesions and only one synchronus lesions have been reported so far. ${ }^{1}$ In our case, both undescended testes were in abdominal cavity giving rise to synchronus bilateral tumors.

Dramatic improvements in survival rate have resulted from the combination of effective diagnostic techniques, improvement in serum tumor markers, effective multidrug chemotherapeutic regimens and modifications of surgical techniques during last 20 years. ${ }^{2}$ The principles of management are the same as those of primary germ cell tumor of testis. The treatment should be based on clinical stage and the most malignant component of the tumor. The survival in patients in bilateral testicular cancers is similar as that of unilateral tumors. ${ }^{7,8,10}$. Follow up of the patient should be for lifelong including chest $\mathrm{x}$-ray and serum level of AFP, $\mathrm{a}-\mathrm{hCG}$ and LDH.

\section{CONCLUSIONS}

Seminoma is the most common type of testicular tumor in cryptorchidism. Bilateral testicular tumors occur metachronously in most of the patients. Synchronus bilateral tumors in bilateral cryptochidism are very rare and this is probably the second case reported in the world literature.

\section{REFERENCES}

1. Kumar P, Kumar R, Tiwary SK, Khanna AK. Bilateral synchronous testicular germ cell tumours in a patient with bilateral cryptorchidism. S Afr J Surg. 2012 Jul 11;50(3):96-7.

2. Haque MM, Siddique AB, Rabbani ABMG, Quasem MA, Rahman AKMG, Rahman MM. Seminoma in undescended intra abdominal testis: a case report. TAJ: Journal of Teachers Association. 2005;18(2):131-3.

3. Whitaker RH. The undescended testis - the risk of malignant degeneration. Monogr Paediatr. 1981;12:104-8.

4. Hai AA, SrivastsvaRB. Text book of surgery. 1st ed. New Delhi: Tata McGraw Hill; 2003. p. 870.

5. Koh KB. Beware the undescended testis and abdominal mass. Aust N Z Surg. 1996;66:851-3.
6. Cheng C, Chan PS. Cryptorchism with a large abdominal mass--a challenge. Br J Urol. 1993 Dec;72(6):946-8.

7. Hoekstra HJ, Mehta DM, Koops HS. Synchronous bilateral primary germ cell tumor of the testis: a case report and review of the literature. J Surg Oncol. 1983 Jan;22(1):59-61.

8. Coogan CL, Foster RS, Simmons GR, Tognoni PG, Roth BJ, Donohue JP. Bilateral testicular tumors: management and outcome in 21 patients. Cancer. 1998 Aug 1;83(3):547-52.

9. Dieckmann KP, Boeckmann W, Brosig W, Dieter I, Bauer HW. Bilateral testicular germ cell tumors. Cancer. 1986;51:1254-8.

10. Patel SR, Richardson RL, Kvols L. Synchronous and metachronous bilateral testicular tumors. Mayo Clinic experience. Cancer. 1990;65:1-4. 